\title{
Correction to: Bioaccumulation of Total Mercury (THg) in Catfish (Siluriformes, Ariidae) with Different Sexual Maturity from Cananéia- Iguape Estuary, SP, Brazil
}

\author{
Giulliana D. Pecoraro ${ }^{1} \cdot$ Marcos A. Hortellani $^{2} \cdot$ Yuri S. Hagiwara ${ }^{1} \cdot$ Elisabete S. Braga ${ }^{3} \cdot$ Jorge E. Sarkis $^{2}$. \\ Juliana S. Azevedo ${ }^{1}$
}

Published online: 12 December 2018

(c) Springer Science+Business Media, LLC, part of Springer Nature 2018

\section{Correction to: \\ Bulletin of Environmental Contamination and Toxicology https://doi.org/10.1007/s00128-018-2485-3}

The original version of the article contained a mistake in the unit values. In the fourth paragraph of "Materials and Methods" section, the fourth sentence should read as: The obtained detection and quantification limits were $0.408 \mathrm{ng}$ $\mathrm{g}^{-1}$ and $3.619 \mathrm{ng} \mathrm{g}^{-1}$, respectively, with circa $90 \%$ recovery compared with DORM-4, showing high precision and accuracy of the THg determination.

The original article has been corrected.

The original article can be found online at https://doi.org/10.1007/ s00128-018-2485-3.

Juliana S. Azevedo

juliana_azevedo@msn.com; juliana.azevedo@unifesp.br

1 Institute of Environmental, Chemical and Pharmaceutical Sciences, Federal University of São Paulo, Diadema, Brazil

2 Institute of Energy and Nuclear Research, São Paulo, Brazil

3 Institute of Oceanography, University of São Paulo, São Paulo, Brazil 